\title{
A scientometric analysis of ICT-assisted disaster management
}

\author{
Sandeep Kumar Sood ${ }^{1} \cdot$ Keshav Singh Rawat $^{2}$
}

Received: 18 September 2019 / Accepted: 6 January 2021 / Published online: 22 January 2021 (c) The Author(s), under exclusive licence to Springer Nature B.V. part of Springer Nature 2021

\begin{abstract}
In recent years, natural and manmade disasters such as floods, earthquakes, wildfires, and tsunamis have occurred with human losses and environmental deterioration. Henceforth, to reduce the damage caused by these catastrophic events, the administration and government need to track victims and perform synchronized relief efforts on time at the disaster sites. The promising technologies of Internet communication technology (ICT), like the Internet of things, cloud computing, and data analytics, can assist various phases of disaster management. Moreover, the role of higher education spans all stages of disaster management: preparedness, response, and recovery. As educational and research contributions, higher educational institutes are essentially involved in all the disaster management stages to contribute to society broadly. Henceforth, the scientific analysis of disaster management literature is required to analyze the overall structure and developments in this domain. This study presents a scientometric analysis that evaluates the ICT-assisted disaster management research over the last 15 years (2005-2020). It presents various empirical ways to analyze the evolution, status, and result of ICT-assisted in disaster management research. This study provides extensive insight into the publication growth, citation analysis, collaboration, and keyword co-occurrence analysis for technological trends of the ICT-assisted disaster management research. It identifies key journals, countries, and organizations that significantly contributed to this research domain. Overall, this study presents various patterns, research trends, and collaborations as the basic structure for future research in this field.
\end{abstract}

Keywords Disaster management $\cdot$ Scientometric $\cdot$ Internet communication technology (ICT) $\cdot$ Higher education $\cdot$ CiteSpace

Sandeep Kumar Sood san1198@gmail.com

Keshav Singh Rawat keshav79699@gmail.com

1 Department of Computer Applications, National Institute of Technology Kurukshetra, Haryana, India

2 Department of Computer Science and Informatics, Central University of Himachal Pradesh, Dharamshala, India 


\section{Introduction}

Disasters such as earthquakes, floods, hurricanes, tsunamis, terror attacks, and disease epidemics not only challenge societies but also peril the human's lives, finance, and security with environmental loss (Kaur and Sood 2019; Shan et al. 2019). In 2015, a total of 22,764 live losses were caused by a natural disaster, 110.3 million, and financial losses of US\$ 70.3 in billion worldwide (Debarati et al. 2016). Humans cannot prevent natural disasters, but estimation and preparation can reduce the different perilous consequences and harm of such incidents too much extent. Therefore, organizations and administration of various countries are preparing a move to disaster management. Disaster management is a continuous collaborative procedure involving governments, disaster management agencies, responders, and societies. Disaster management research is demanding due to its significant social and economic implications. Many papers have been published on disaster management related to disaster preparedness, response, and recovery to minimize the disruption and live losses.

In the recent decade, the growth rate of technological innovation in ICT is increasing rapidly, and its application is integrated with interdisciplinary research. With the advancement of ICT in remote sensing, global information systems, satellite communication, Internet of things (IoT), cloud computing, sensor networks, ad hoc network, data mining, and Internet offer approaches to plan and implement risk reduction in disaster (Kamruzzaman et al. 2017). The risk can be reduced using these technologies to design systems in all phases of disaster (preparedness, response, and recovery) (Verrucci et al. 2016). Hence, ICT has a major role in all the phases of disaster management.

Moreover, higher education supports educational and research contributions through ICT technologies to minimize the harm caused by disaster activities. Therefore, higher education institutions are required to take responsibility for disaster-related education, training, and research to build a more responsive professional environment at the time of disaster (Thayaparan et al. 2014).

Despite the large number of publications related to disaster management research, to understand the evolution, status, and result of disaster management research based on ICT published from 2005 to 2020 , the research literature of this domain has been quantitatively analyzed. Scientometrics offers various features for quantitative analysis of literature. It also offers improvement and enhancement in the research domain.

The scientometric studies have been performed in different areas such as, Internet of things (Sinha et al. 2019), cloud computing (Heilig and VoAY 2014), big data analytics (Xu and Yu 2019), geographic science (Biljecki 2016), health care (Galetsi and Katsaliaki 2019), and disaster emergency management (Du et al. 2020). The study is unique as no publication covers recent time spam during 2005-2020 and used CiteSpace visualizations. Therefore, scientometric analysis is required to include whole fundamental research in the field of disaster management.

\subsection{Focus and objectives}

The disaster can be classified into two types: natural and manmade disaster (Barnes et al. 2019). Natural disasters are occurred due to the physical and biotic nature of environmental events. It is classified into three categories: geophysical, meteorological, and biological disaster (Guha-Sapir et al. 2012). A geophysical disaster is caused due to seismic or 
tectonic activities under the earth. The meteorological disaster is caused due to sudden and destructive variations in the weather conditions in the environment. Biological disasters are caused due to living organisms spread in our environment enormously and source of diseases or epidemic. Catastrophic events cause manmade disasters. However, over time, new categories, i.e., technological disasters come into existence. Technological disasters are occurred due to the breakdown of industrial machinery or technologies. The main foundations related to disaster management research are preparedness, response, and recovery (King 2007).

The core objectives of this paper include (1) to present a scientometric analysis of research in ICT-assisted disaster management from 2005 to 2020, (2) to discover the scientometric features of ICT-assisted disaster management research in various subcategories of disasters, (3) to reveal the significant subcategories, collaborations, and research topics using various scientometric analyses, and (4) to identify influential journals and organizations in the field of ICT-assisted disaster management research.

\subsection{Contribution}

This study identifies the scientometric patterns in the field of ICT-assisted disaster management from 2005 to 2020. The major contributions of this study are: (1) This study contributes to various empirical methods to analyze the evolution, status, and research results in this domain, (2) this paper contributes to analyzing keyword co-occurrence analysis for technological trends of the ICT-assisted disaster management research, and (3) this study contributes to discovering the essential subcategories and research topics in this domain for future research.

The study is organized to depict various aspects of scientometric analysis in ICTassisted disaster management. The remaining paper is depicted as follows. In Sect. 2, data collection, a visualization tool, and methodology are discussed. Section 3 discusses the patterns of research publication. In Sect. 4, the international collaboration of literature is analyzed and discussed. Section 5 discusses the citation analysis of research literature, including top cited documents, influential journals, and institutions. In Sect. 6, the keyword co-occurrence network is analyzed for technological trends. At last, Sect. 7 concludes this study.

\section{Data collection and methodology}

The Scopus core collection is used as the data source for assessing bibliometric data related to disaster management. The Scopus is a leading multidisciplinary database that provides a well-organized structure for categorizing the subject domain (Sahil and Sood 2020). The term "disaster management" was used in the search query for downloading data set from Scopus. The search result is refined by setting the research subject "computer science," the language "English," and publication period from 2005 to 2020 and retrieved a dataset of 3294 documents in CSV (comma-separated values) and RIS (Research Information Systems) file formats using query (TITLE-ABS-KEY ("disaster management”) AND PUBYEAR > 2004 AND PUBYEAR < 2021 AND (LIMIT- TO (SUBJAREA, “COMP”)) AND (LIMIT-TO (LANGUAGE, "English"))). The detail of the search query is described in Table 1 that used to download the dataset from the Scopus database. 
Table 1 Scopus query

\begin{tabular}{ll}
\hline Data source & Scopus \\
\hline Search query & TITLE-ABS-KEY ("disas- \\
ter management") AND & PUBYEAR>2004 AND \\
& PUBYEAR<2021 AND \\
& (LIMIT- TO (SUBJAREA, \\
& "COMP”)) AND (LIMIT-TO \\
& (LANGUAGE, "English")) \\
& H-Index, CiteScore, SJR \\
Quality measure & SCImago Journal Rank and \\
& Source Normalized Impact per \\
& Paper \\
Time span & January 2005 to August 2020 \\
Retrieval time & July 2020 to August 2020 \\
No of records & 3294 \\
\hline
\end{tabular}

\subsection{CiteSpace}

CiteSpace is used in this study to analyze research literature that depicts the structure of scientific knowledge in terms of analysis and visualization of data to express various knowledge graphs. It is a Java-based free tool and available on the Internet (Chen 2019). The other most common softwares for visualization are VOSviewer (van Eck and Waltman 2010, 2014), Gephi tool (Jacomy et al. 2014), and SciMAT(Cobo et al. 2012). However, CiteSpace is a more powerful software that uses betweenness centrality $(\mathrm{BC})$ to recognize the pivot points of literature. In CiteSpace, users can set the analysis duration of the research publication, thresholds, and many other options. CiteSpace visualization is depicted as nodes and links, where nodes represent authors, journals, nations, keywords, organizations, and others, and links represent the relationship among them. In visualization, the large node depicts publication / citation frequency, and the nodes having a purple ring and red inner ring represent centrality measure and the burst of research, respectively (Chen and Wu 2017; Chen 2017). In this study, two types of analysis networks are visualized using the CiteSpace: international collaboration and keyword co-occurrence. The various parameters of CiteSpace, such as time duration, type of node, link, threshold selection, and pruning algorithms, are to be set during the execution of international collaboration and keyword co-occurrence analysis (Huang et al. 2020; Song et al. 2016). The parameter settings of CiteSpace for international collaboration analysis were fixed as: (a) time slicing: January 2005-August 2020, years per slice: 01; (b) type of node: country; (c) selection criteria: g-index (scale factor $\mathrm{k}=25$ ); (d) pruning: none; and (e) other parameters: default value. The parameter settings of CiteSpace for keyword co-occurrence analysis were fixed as: (a) time slicing: January 2005-August 2020, years per slice: 01; (b) type of node: keyword; (c) selection criteria: g-index (scale factor $\mathrm{k}=10$ ); (d) pruning: pathfinder; and (e) other parameters: default value

\section{Publication pattern}

The growth and trends in the 3294 documents retrieved through the Scopus database of the various subcategories of the disaster of the last 15 years are shown in Fig. 1. As can be seen from the figure, the quantity of documents on disaster management has experienced 
slow growth at the beginning (2005-2010) and rapid growth after that (2011-2020). Earthquake (928) and flood (833) subcategories have the maximum number of documents with rapid growth from 2012 to 2020 . The number of documents in the disease epidemic subcategory is increased after the COVID-19 pandemic. Figure 1a represents the growth trends in the categories of disaster management, and the geophysical and hydro-meteorological disaster have identified the maximum share of articles during 2005-2020. Figure 1b shows the trends in the subcategories of hydro-meteorological disaster and identified flood followed by the cyclone are the two leading subcategories. Figure 1c depicts the growth in the geophysical category with an earthquake subcategory contains the maximum number of occurrences. Figure 1d, e, f depicts the growth of publication in the biological, technological, and humanistic subcategories, respectively.

\section{International collaborations}

In this section, the international collaboration of literature is analyzed using the CiteSpace visualization map. Figure 2 depicts the collaboration network among various contributed countries related to disaster management literature from 2005 to 2020 with 58 nodes and

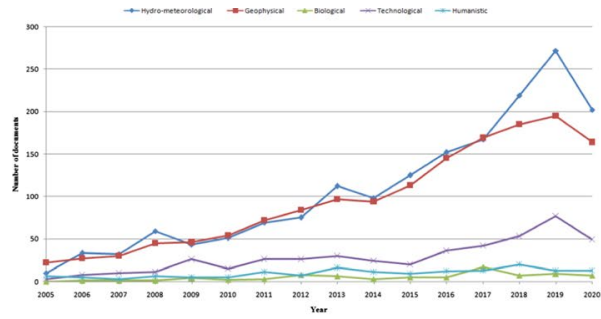

(a) Major categories of disaster

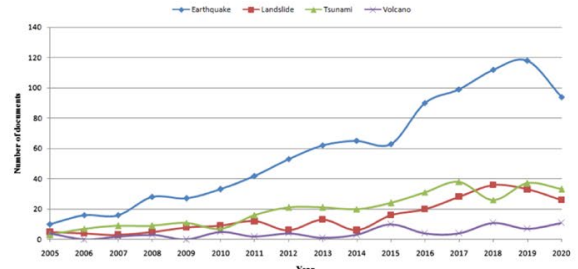

(c) Geophysical

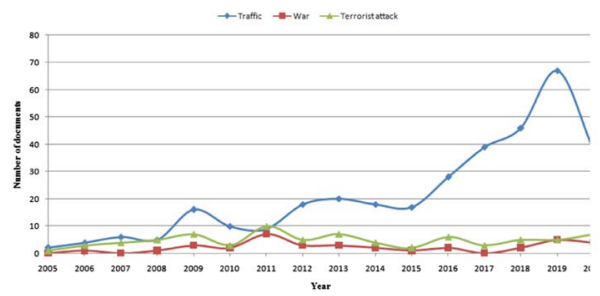

(e) Technological

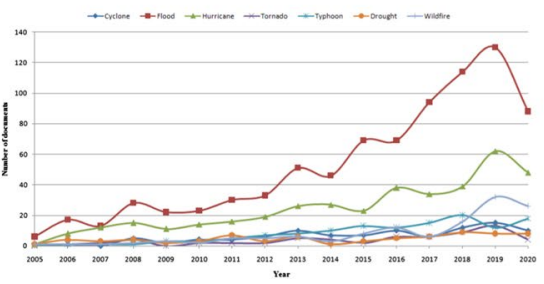

(b) Hydro-meteorological

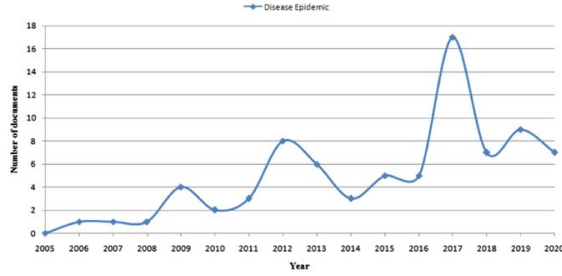

(d) Biological

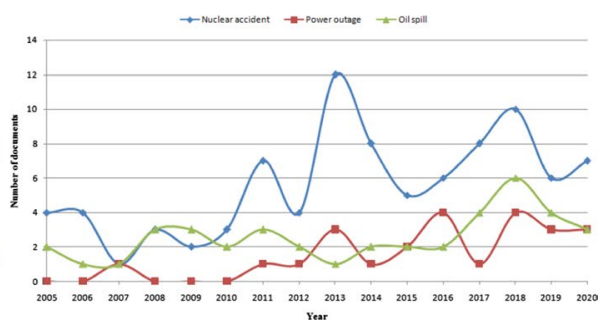

(f) Humanistic

Fig. 1 Publication growth of various categories of ICT-assisted disaster management literature from 2005 to 2020 
342 links. In a network, each node depicts a nation, and node size represents the quantity of publication contribution through the individual nation. After analyzing the network, it is observed that most of the countries belong to Europe, North America, and Asia are the pivot point of this research domain and containing higher betweenness centrality. The top leading contributed countries in this field are listed in Table 2. As shown in the table, India (544) and USA (499) are the top contributors in this research domain. The USA (0.39) has the most betweenness centrality, followed by India (0.30) and Japan (0.18). Moreover, it is also identified that both developed and developing nations are actively participating in this research domain.

\section{Citation analysis}

In this paper, the impact and importance of the research are determined by citation counts and normalized citation impact index (NCII). The NCII is defined as the ratio between citation counts per document and the publication longevity in Eq. 1 (Kaur and Sood 2020).

$$
\mathrm{NCII}=\frac{\text { citation counts per document }}{\text { publication longevity }}
$$

The year-wise citation analysis of disaster management research literature from 2005 to 2020 is shown in Fig. 3. The total citation count, average citations per publication, and h-index are $26219,7.95$, and 63, respectively. The received citation count is increased during 2005-2020 that shows the significance of this research area.

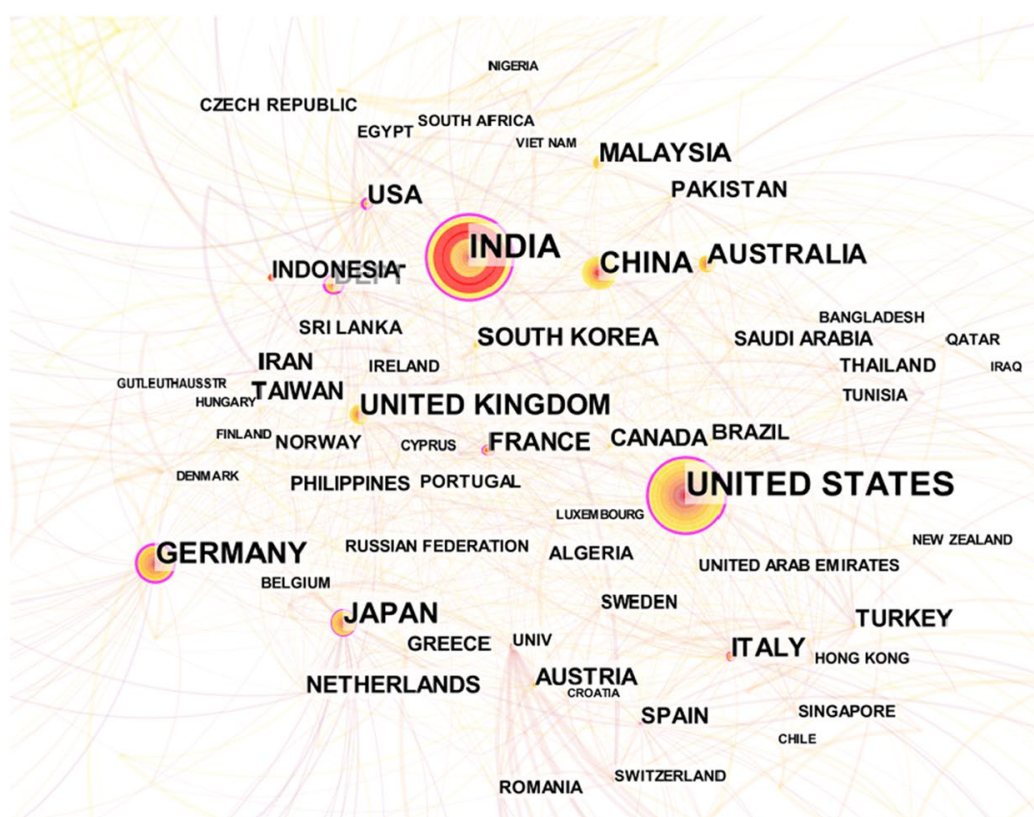

Fig. 2 Collaboration network of different countries 
Table 2 Top ten most productive nations

\begin{tabular}{llrrl}
\hline Rank & Country name & $n$ & $n(\%)$ & BC \\
\hline 1 & India & 544 & 16.51 & 0.31 \\
2 & USA & 499 & 15.15 & 0.39 \\
3 & Germany & 282 & 8.56 & 0.3 \\
4 & China & 258 & 7.83 & 0.09 \\
5 & Japan & 209 & 6.34 & 0.18 \\
6 & UK & 193 & 5.86 & 0.09 \\
7 & Australia & 155 & 4.71 & 0.04 \\
8 & Malaysia & 119 & 3.61 & 0.06 \\
9 & Italy & 111 & 3.37 & 0.11 \\
10 & France & 95 & 2.88 & 0.11 \\
\hline
\end{tabular}

\subsection{Citation output}

Figure 4 shows the category-wise citation counts trends of disaster management literature from 2005 to 2020 . Figure 4 a depicts the citation distribution among various categories of disaster, such as hydro-meteorological (44.0\%), geophysical (36.3\%), biological $(2.6 \%)$, technological $(11.6 \%)$, and humanistic $(5.4 \%)$. After analyzing citations of Fig. $4 \mathrm{~b}$, it has been found that the publication of flood subcategory received the highest citation $(40.3 \%)$, followed by the hurricane $(29.3 \%)$ and wildfire $(12.1 \%)$. The subcategory of the earthquake possesses the highest percentage of citation (66.6\%) among other subcategories, as shown in Fig. 4c. Figure 4d shows the citation trend of the biological category, and after 2014, the rapid growth has been noticed in the received citations. The subcategory of traffic accidents (84.6\%) in Fig. 4e and subcategory of nuclear accidents $(61.9 \%)$ possess the maximum citation counts. The analysis depicts that the subcategory of the earthquake, flood, and traffic accidents have received the highest citation counts among all the subcategories, which show the significance and impact of research in this field.

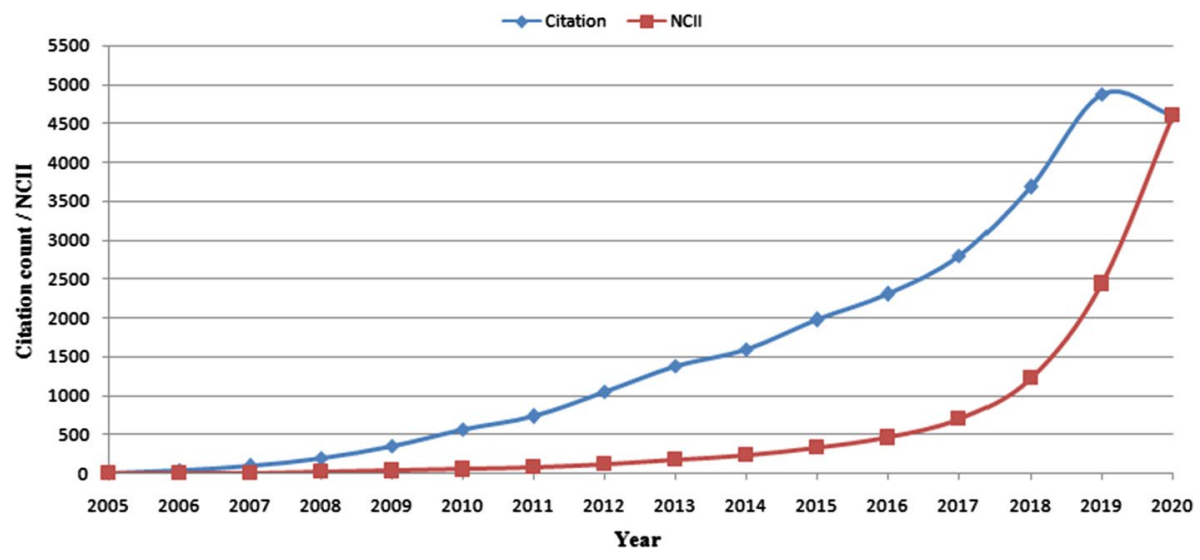

Fig. 3 Trends of citation counts and NCII 


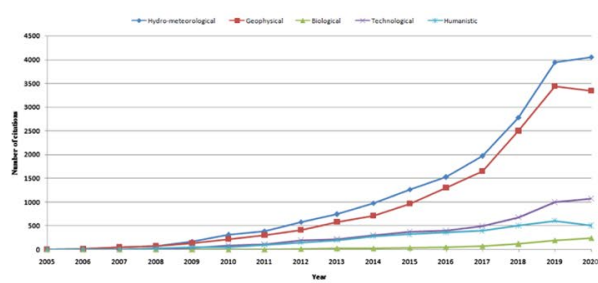

(a) Major categories of disaster

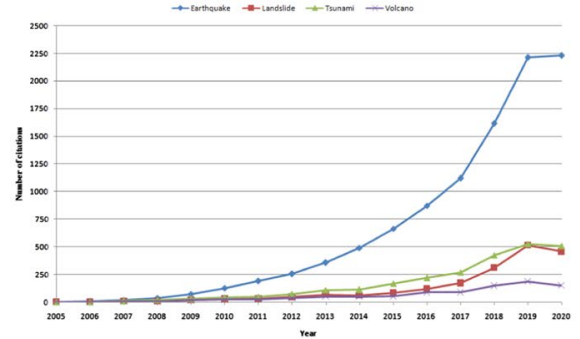

(c) Geophysical

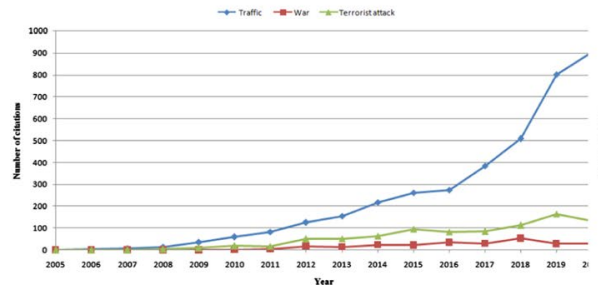

(e) Technological

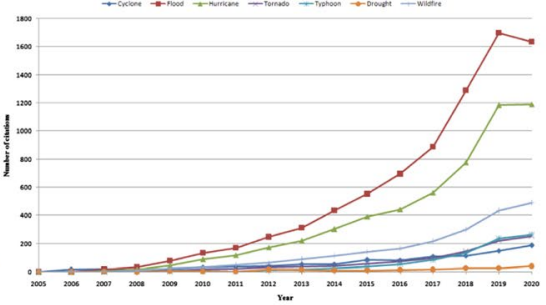

(b) Hydro-meteorological

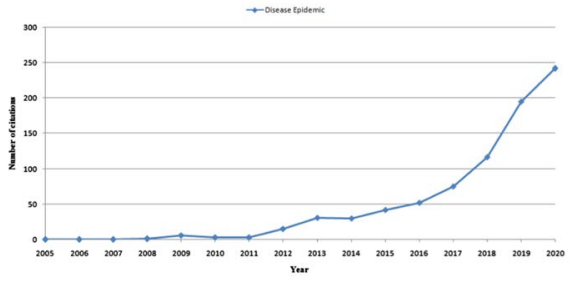

(d) Biological

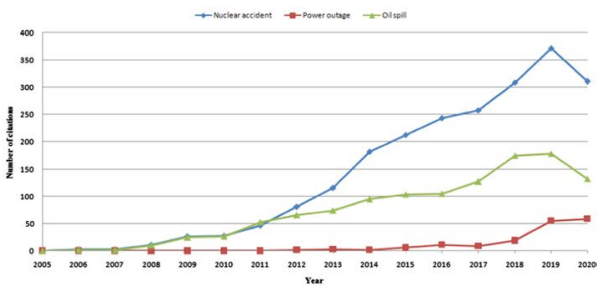

(f) Humanistic

Fig. 4 Category-wise citation trends of ICT-assisted disaster management literature from 2005 to 2020

\subsection{Highly cited documents}

The analysis of the highly cited documents assists in identifying the base literature of research. In this section, the influential documents are identified based on the received citation counts, and their NCII in the field of ICT-assisted disaster management research from 2005 to 2020. Table 3 lists the top 30 most cited documents based on citation counts and NCII with attributes document title, author name, source title, year, citation, and NCII. The NCII is utilized to eliminate the temporal effect of citations counts and compare publications from different years. After analyzing Table 3, it is observed that $47 \%$ of publications are related to survey and review based on the list that helps to identify the fundamental structure of research. Moreover, the analysis identifies these core works of literature and is divided into the following areas-artificial intelligence, Internet of things, wireless sensor networks, crowdsourcing, remote sensing, social network analysis, unmanned aerial vehicles, satellite, and social media. Table 3 lists the most cited documents "A survey on clustering algorithms for wireless sensor networks" published by Computer Communications (Abbasi and Younis 2007) followed by "OR/MS research in disaster operations management" (Altay and Green 2006) and "People at risk of flooding: Why some residents take precautionary action while others do not" published by Natural Hazards (Grothmann and 


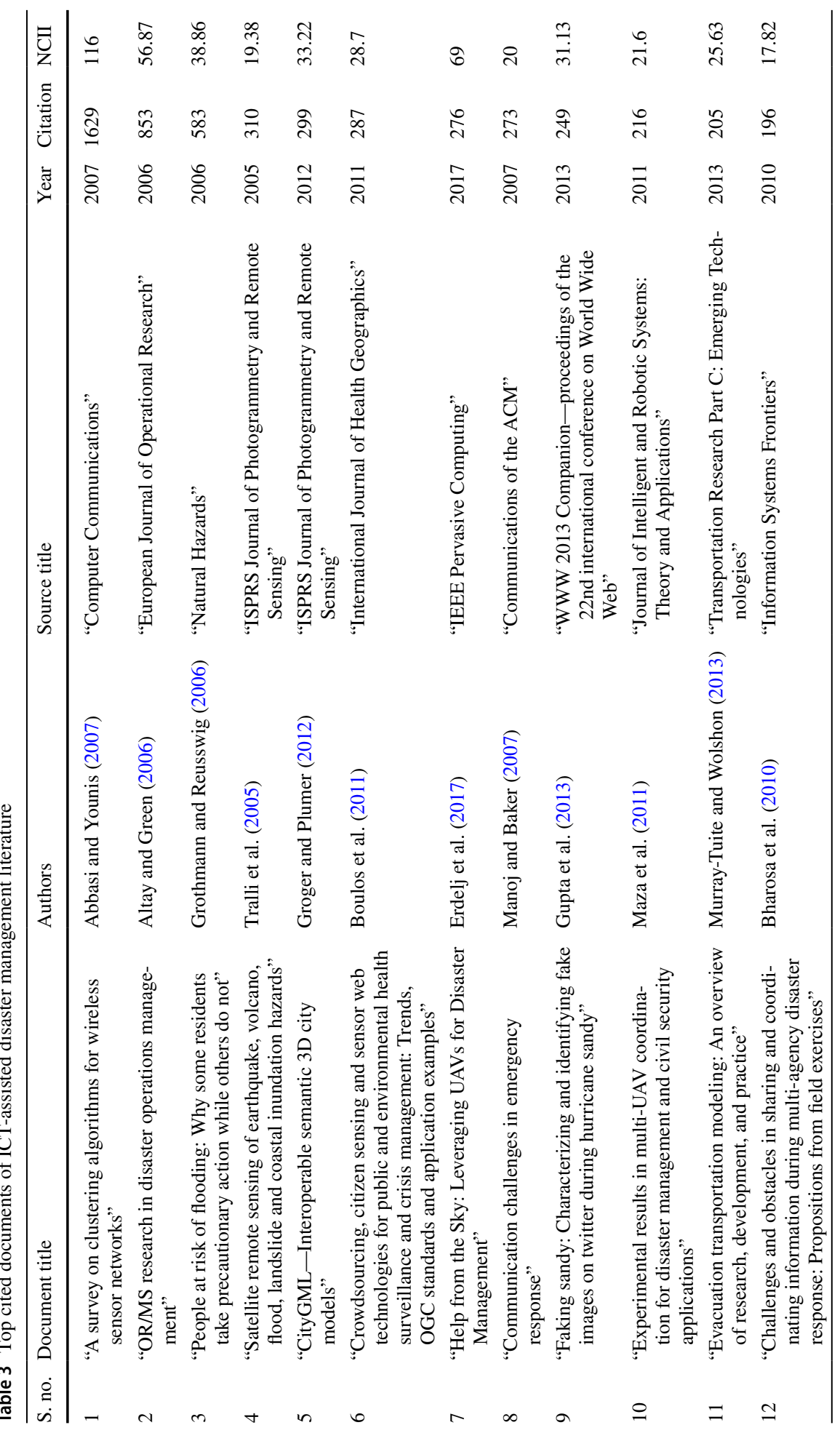




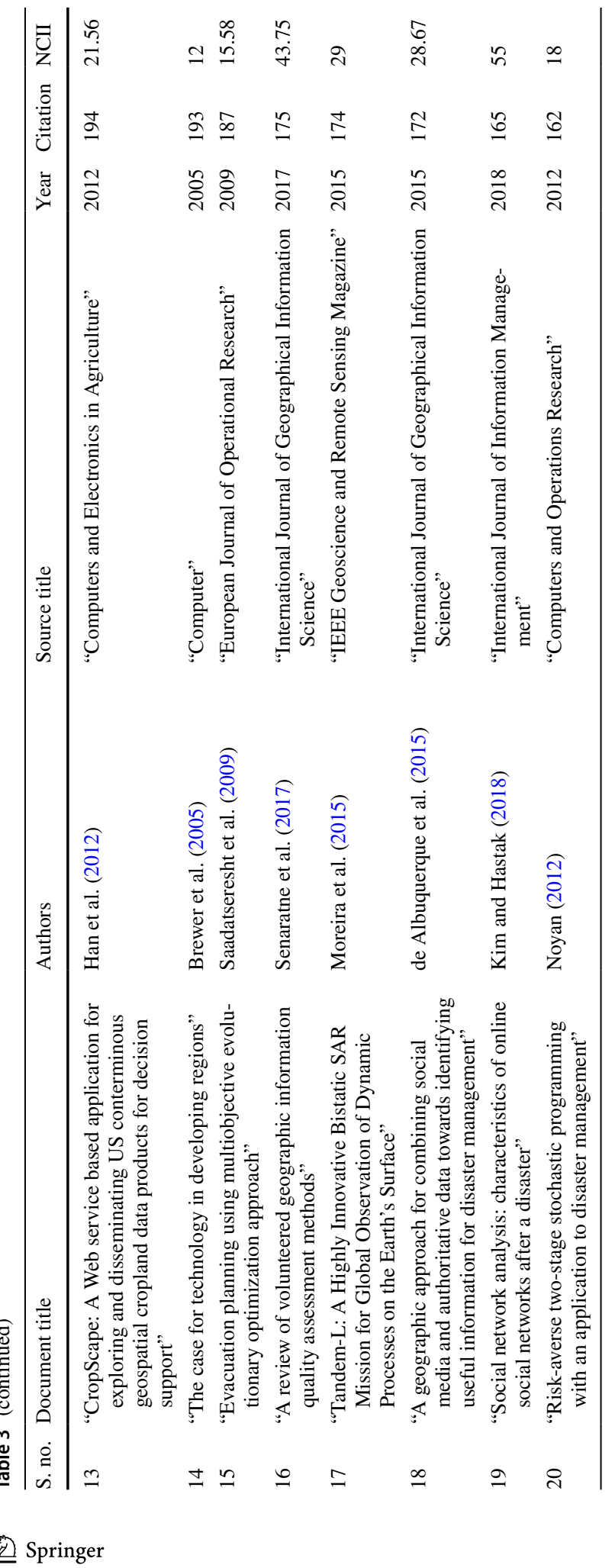


Reusswig 2006). Abbasi and Younis (2007) received the maximum citations of 1629 with NCII value 116. Altay and Green (2006) and Grothmann and Reusswig (2006) have citations 853 and 583, respectively. The top cited article Abbasi and Younis (2007) has studied related to employability of wireless sensor networks in disaster management, security surveillance, combat field, and others. It surveys various clustering techniques for wireless sensor networks, their features, objectives, complexities, and their comparison based on cluster stability, convergence rate, and location awareness. Altay and Green (2006) surveyed the literature related to OR/MS to recognize publication trends and issues for future research. Grothmann and Reusswig (2006) studied self-protective behavior, risk, and possible consequences during the flood.

\subsection{Influential journals}

The choice of the correct journal affects the reach and impact of scientific writing. Henceforth, it is essential to assess journal influence in the research domain. In this paper, citation information is used to evaluate the influence of journals in ICT-assisted disaster management research literature. Table 4 represents the highly cited journals of various categories of disaster management with their document frequency $(n)$, publication share $(n \%)$, total citation counts (TC), citations/publication (TC/n), and impact factor (IF). The impact factor is the most commonly used scientometric measure that is determined by evaluating the average citations received in the two preceding years by the journal. Moreover, the average citation $(\mathrm{TC} / n)$ is used to determine the impact of a journal with different research areas. Therefore, IF and TC/n are used to determine the impact of a journal related to disaster management. As given in Table 4, the European Journal of Operational Research and Natural Hazards are top cited journals in hydro-meteorological, Geophysical, Biological, and Humanistic category. The hydro-meteorological category has "European Journal of Operational Research" (1595) with an impact factor of 4.21 followed by "Natural Hazards" (845) with an impact factor of 2.42 as highly cited journals. "European Journal of Operational Research" and "Natural Hazards" have citations $(1567,956),(169,146),(882,165)$ for Geophysical, Biological, and Humanistic categories, respectively. The technological category has "European Journal of Operational Research" (1194) and "Transportation Research Part C: Emerging Technologies" (381) as the most cited journals. The highest impact factor hold by "IEEE Geoscience and Remote Sensing Magazine" (10.28), followed by the "IEEE Internet of Things Journal" (9.51) and "International Journal of Information Management" (8.21) in all categories. Furthermore, the grouping of high impact factor and documents quantity of journals are also used to reveals the importance in the research area, such as by "IEEE Geoscience and Remote Sensing Magazine" $(10.28,2)$ in the humanistic category, "IEEE Internet of Things Journal" $(9.51,3)$ in the technological category, "International Journal of Information Management" $(8.21,8)$ in the geophysical category, "International Journal of Information Management" $(8.21,9)$ in the hydro-meteorological category, and "Transportation Research Part C: Emerging Technologies" $(7.02,2)$ in the biological category.

\subsection{Influential institutions}

In this section, prominent institutions are identified for measuring the impact of research in that organization. Table 5 depicts the most cited institutions of various categories of disaster management with their document frequency $(n)$, total citation counts (TC), and citation 
Table 4 Influential journals in each category of ICT-assisted disaster management literature

\begin{tabular}{|c|c|c|c|c|c|c|}
\hline Category & Name of journal & $n$ & $n(\%)$ & $\mathrm{TC}$ & $\mathrm{TC} / n$ & IF \\
\hline \multirow[t]{6}{*}{ Hydro-meteorological } & European Journal of Operational Research & 17 & 1.44 & 1595 & 93.82 & 4.21 \\
\hline & Natural Hazards & 16 & 1.36 & 845 & 52.81 & 2.42 \\
\hline & $\begin{array}{l}\text { International Journal of Geographical Informa- } \\
\text { tion Science }\end{array}$ & 14 & 1.19 & 585 & 41.79 & 3.73 \\
\hline & $\begin{array}{l}\text { Transportation Research Part C: Emerging } \\
\text { Technologies }\end{array}$ & 9 & 0.76 & 445 & 49.44 & 6.08 \\
\hline & $\begin{array}{l}\text { International Journal of Information Manage- } \\
\text { ment }\end{array}$ & 9 & 0.76 & 334 & 37.11 & 8.21 \\
\hline & Information Systems Frontiers & 7 & 0.59 & 268 & 38.29 & 3.71 \\
\hline \multirow[t]{6}{*}{ Geophysical } & European Journal of Operational Research & 16 & 1.42 & 1567 & 97.94 & 4.21 \\
\hline & Natural Hazards & 15 & 1.33 & 956 & 63.73 & 2.42 \\
\hline & Computers and Geosciences & 11 & 0.97 & 340 & 30.91 & 2.99 \\
\hline & $\begin{array}{l}\text { International Journal of Information Manage- } \\
\text { ment }\end{array}$ & 8 & 0.71 & 333 & 41.63 & 8.21 \\
\hline & $\begin{array}{l}\text { Transportation Research Part C: Emerging } \\
\text { Technologies }\end{array}$ & 6 & 0.53 & 315 & 52.50 & 6.08 \\
\hline & $\begin{array}{l}\text { Computer-Aided Civil and Infrastructure } \\
\text { Engineering }\end{array}$ & 12 & 1.06 & 171 & 14.25 & 7.02 \\
\hline \multirow[t]{6}{*}{ Biological } & European Journal of Operational Research & 4 & 4.82 & 169 & 42.25 & 4.21 \\
\hline & Natural Hazards & 4 & 4.82 & 146 & 36.50 & 2.42 \\
\hline & $\begin{array}{l}\text { Computer-Aided Civil and Infrastructure } \\
\text { Engineering }\end{array}$ & 2 & 2.41 & 59 & 29.50 & 7.02 \\
\hline & IEEE Access & 2 & 2.41 & 19 & 9.50 & 3.75 \\
\hline & Journal of Network and Computer Applications & 2 & 2.41 & 19 & 9.50 & 5.57 \\
\hline & Computer Communications & 2 & 2.41 & 6 & 3.00 & 2.82 \\
\hline \multirow[t]{6}{*}{ Technological } & European Journal of Operational Research & 6 & 1.43 & 1194 & 199.00 & 4.21 \\
\hline & $\begin{array}{l}\text { Transportation Research Part C: Emerging } \\
\text { Technologies }\end{array}$ & 9 & 2.14 & 381 & 42.33 & 6.08 \\
\hline & $\begin{array}{l}\text { International Journal of Geographical Informa- } \\
\text { tion Science }\end{array}$ & 9 & 2.14 & 208 & 23.11 & 3.73 \\
\hline & $\begin{array}{l}\text { Computer-Aided Civil and Infrastructure } \\
\text { Engineering }\end{array}$ & 6 & 1.43 & 145 & 24.17 & 7.02 \\
\hline & Natural Hazards & 8 & 1.90 & 141 & 17.63 & 2.42 \\
\hline & IEEE Internet of Things Journal & 3 & 0.71 & 43 & 14.33 & 9.51 \\
\hline \multirow[t]{6}{*}{ Humanistic } & European Journal of Operational Research & 2 & 2.63 & 882 & 441.00 & 4.21 \\
\hline & Natural Hazards & 2 & 2.63 & 165 & 82.50 & 2.42 \\
\hline & $\begin{array}{l}\text { Transportation Research Part C: Emerging } \\
\text { Technologies }\end{array}$ & 2 & 2.63 & 39 & 19.50 & 6.08 \\
\hline & IEEE Access & 2 & 2.63 & 33 & 16.50 & 3.75 \\
\hline & $\begin{array}{l}\text { IEEE Geoscience and Remote Sensing Maga- } \\
\text { zine }\end{array}$ & 2 & 2.63 & 15 & 7.50 & 10.28 \\
\hline & $\begin{array}{l}\text { Computer-Aided Civil and Infrastructure } \\
\text { Engineering }\end{array}$ & 2 & 2.63 & 10 & 5.00 & 7.02 \\
\hline
\end{tabular}


counts /publication $(\mathrm{TC} / n)$. The analysis identified that $50 \%$ of top cited organizations in the list belong to the USA (10), followed by India (4). University of Richmond of the USA has received the maximum citations of 856 in the humanistic category, followed by Georgia Institute of Technology of the USA (277) in the geophysical category, and the Delft University of Technology of The Netherlands (253) in the hydro-meteorological category. It is observed that Florida International University, USA, and Purdue University, USA, have produced the highest publications. Moreover, the Georgia Institute of Technology of the USA (138.5), followed by the Delft University of Technology of the USA (126.5), has received the maximum average citation counts/publications. However, it is analyzed that the top cited institution's research work in the biological category of disaster management is exceptionally less that depicts the scope in the disaster management domain for future research.

\section{Keyword co-occurrence analysis for technological trends}

Keyword co-occurrence has an essential role in the scientometric analysis. Keywords depict the core representation of documents and key topics of research. In this paper, keyword co-occurrence analysis is used to identify research hot spots and frontiers in this domain.

Table 5 Influential institutions in each category of ICT-assisted disaster management literature

\begin{tabular}{|c|c|c|c|c|c|}
\hline Category & Name of Institution & Country & $\mathrm{TC}$ & $n$ & $\mathrm{TC} / n$ \\
\hline \multirow[t]{4}{*}{ Hydro-meteorological } & Delft University of Technology & The Netherlands & 253 & 2 & 126.5 \\
\hline & Purdue University & USA & 207 & 2 & 103.5 \\
\hline & Florida International University & USA & 72 & 4 & 18 \\
\hline & King Khalid University & Saudi Arabia & 60 & 2 & 30 \\
\hline \multirow[t]{4}{*}{ Geophysical } & Georgia Institute of Technology & USA & 277 & 2 & 138.5 \\
\hline & $\begin{array}{l}\text { Indraprastha Institute of Information Technol- } \\
\text { ogy }\end{array}$ & India & 252 & 2 & 126 \\
\hline & Purdue University & USA & 120 & 4 & 30 \\
\hline & Institute for Informatics and Telematics & Italy & 112 & 2 & 56 \\
\hline \multirow[t]{4}{*}{ Biological } & Arizona State University & USA & 28 & 1 & 28 \\
\hline & Imperial College London & UK & 13 & 2 & 6.5 \\
\hline & Heritage Institute of Technology & India & 14 & 2 & 7 \\
\hline & $\begin{array}{l}\text { Indian Institute of Engineering Science and } \\
\text { Technology }\end{array}$ & India & 14 & 2 & 7 \\
\hline \multirow[t]{4}{*}{ Technological } & Tehran University & Iran & 188 & 2 & 94 \\
\hline & Joanneum Research & Austria & 133 & 2 & 66.5 \\
\hline & Al-Mustansereya University & Iraq & 108 & 2 & 54 \\
\hline & Swansea University & UK & 108 & 2 & 54 \\
\hline \multirow[t]{4}{*}{ Humanistic } & University of Richmond & USA & 856 & 1 & 856 \\
\hline & Florida International University & UK & 129 & 1 & 129 \\
\hline & University of Tokyo & Japan & 75 & 1 & 75 \\
\hline & Kent State University & USA & 51 & 1 & 51 \\
\hline
\end{tabular}


The keyword co-occurrence network is created using CiteSpace to depict relationships among keywords in ICT-assisted disaster management literature from 2005 to 2020. The parameters in CiteSpace for co-occurrence analysis were set as: (1) time slicing: January 2005-August 2020, years per slice: 01, (2) type of node: keyword, (3) selection criteria: g-index (scale factor $k=10$ ), (4) pruning: pathfinder, and (5) other parameters: default value. Figure 5 represents the keyword co-occurrence network of various keywords related to disaster management literature between 2005 and 2020. In a network, each node depicts a keyword, and node size depicts the occurrence of a keyword. The bigger the node, the higher the occurrence. However, trivial keywords such as disaster, disaster prevention, disaster management, and similar keywords are ignored during the visualization of the keyword co-occurrence network. After analyzing Fig. 5, it is identified that ICT-assisted disaster management research field is related to the research areas: information management, remote sensing, social networking (online), artificial intelligence, wireless sensor network, Internet of thing, big data, data mining, ad hoc network, classification, crowdsourcing, machine learning, deep learning, cloud computing, and sensor network.

Figure 6 depicts the timeline view of technological trends of ICT-assisted disaster management literature during the period 2005-2020. In the map's visualization, the title term and log-likelihood ratios (LLR) weighing algorithms are used to recognize cluster labels. LLR method identifies the cluster labels that depict the core topics of each cluster on the map. As shown in Fig. 6 and Table 6, the nine clusters were recognized with a modularity value (0.46) and a mean silhouette value (0.59). The clustering precision and clustering scale are presented by modularity and mean silhouette values, respectively. Table 6 depicts the summary of the nine clusters with attributes Cluster_ID, Cluster_size, Silhouette_ value, Label(LLR), and Mean (citation year). As per the mean citation year in Fig. 6 and Table 6, each cluster in the map during the period of 2005-2020: (1) cluster 0 (Disasters management), cluster 4 (Emergency management), and cluster 7 (Orthogonal frequencydivision) are the clusters belong to the beginning stage of research literature that depicts the early research work in this domain, such as fuzzy logic, grid computing, image processing, information management, and wireless sensors. (2) Cluster 2 (Emergency action plan), cluster 5 (Emergency management system), cluster 6 (Wireless sensor network),

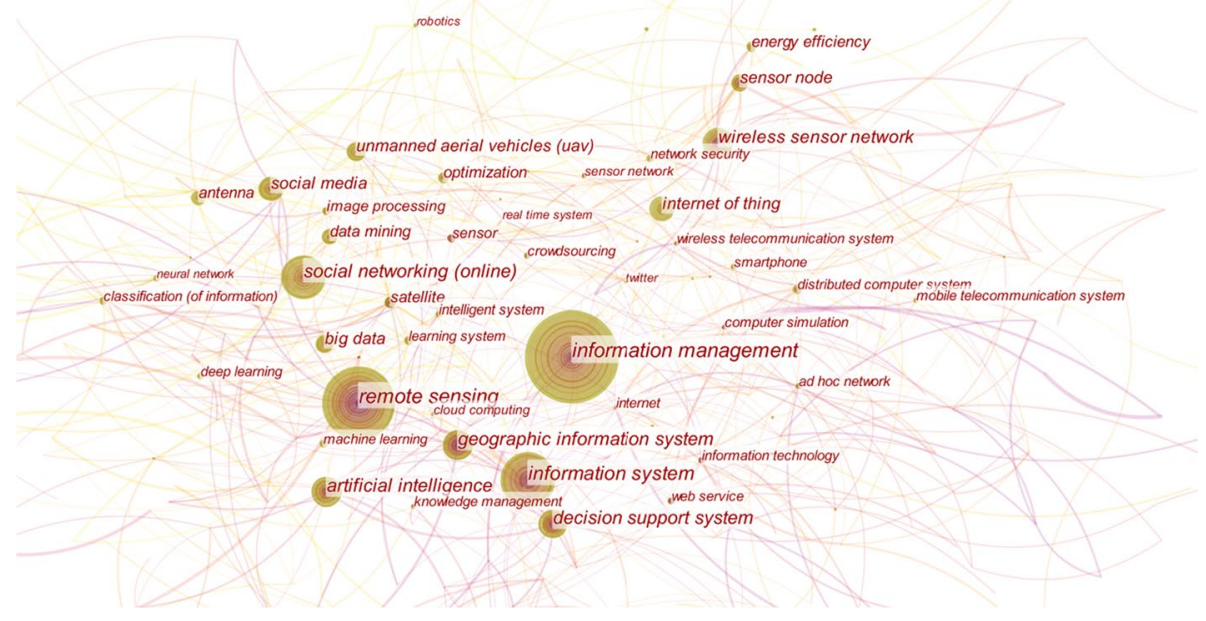

Fig. 5 Technological trends of ICT-assisted disaster management literature 
Table 6 Summary of clusters

\begin{tabular}{lllll}
\hline Cluster_ID & Label (LLR) & Cluster_size & Silhouette_value & Mean (cite year) \\
\hline 0 & Disasters management & 73 & 0.709 & 2010 \\
1 & IoT environment & 59 & 0.607 & 2014 \\
2 & Emergency action plan & 58 & 0.663 & 2010 \\
3 & Learning technique & 58 & 0.71 & 2014 \\
4 & Emergency management & 55 & 0.797 & 2009 \\
5 & Emergency management system & 54 & 0.658 & 2011 \\
6 & Wireless sensor network & 43 & 0.846 & 2010 \\
7 & Orthogonal frequency division & 40 & 0.693 & 2008 \\
8 & Remote sensing data & 14 & 0.869 & 2010 \\
\hline
\end{tabular}

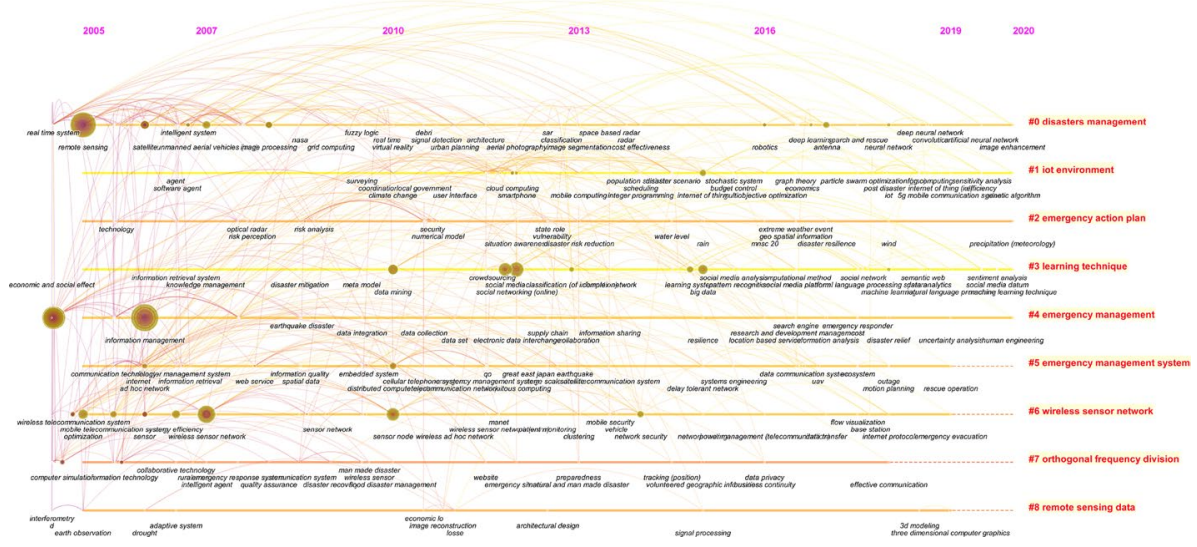

Fig. 6 Year-wise technological trends of ICT-assisted disaster management literature

and cluster 8 (Remote sensing data) with mean citation year 2010 and 2011 present the important research topics of this domain such as embedded systems, cellular communication, distributed computing, ad hoc wireless network, and sensor network. (3) The recent topics in this domain are recognized by cluster 1 (IoT environment) and cluster 3 (Learning technique) that are actively participating areas such as cloud computing, Internet of things, graph theory, data mining, crowdsourcing, learning system, and social media. Furthermore, there has been recent progress in various research areas, including deep neural network, sentimental analysis, cloud computing, IoT, 5G mobile communication, data analytics, and social networking.

\section{Summary and conclusion}

Disaster management research has experienced a paradigm change from reactive to ICTassisted proactive strategies worldwide that are at risk from different natural hazards and manmade disasters. Higher education can support educational and research contributions using ICT technologies to reduce the damage caused by disastrous events. In this 
study, scientometric analysis is presented for the ICT-assisted smart disaster management research literature from 2005 to 2020. This study utilizes the CiteSpace tool for the visualization of data set for better understanding. The study intends to address different bibliometric aspects: publication growth, citation trends, country collaboration, influential journals, influential institutions, and keyword co-occurrence for technological trends of different subcategories of disasters field. The research literature related to disaster management was downloaded from the Scopus database of the period from January 2005 to August 2020.

This study depicted that most research has been done in the earthquake, flood, and transport accident subcategories, and the least documents have been published in the biological category, which shows the extent of research in this area. The growth of publications in disaster management literature has increased in recent years. ICT technologies such as artificial intelligence, the Internet of things (IoT), cloud computing, data mining, and machine learning are identified as significant areas with a rapid transformation in the number of publications and citations. The analysis acknowledged that the subcategory of the earthquake, flood, and traffic accidents had received the highest citation counts among all the subcategories, which present the importance and impact of these research areas. The international collaborations depicted that most contributed countries belong to Europe, North America, and Asia. Collaboration analysis identifies India and the USA as the top contributors in this domain. The citation analysis of top cited journals presented the research impact of the "European Journal of Operational Research" and "Natural Hazards" in various subcategories of this research. The analysis also identified that the "IEEE Geoscience and Remote Sensing Magazine" and "IEEE Internet of Things Journal" have the highest impact factor in various subcategories. The top cited institutions' analysis depicted that most of the influential institutions belonged to the USA and India. Furthermore, it is analyzed that the top cited organization's research work in the biological category of disaster management research was significantly less. The highly cited articles are published in the reputed journals of different countries, and most of the articles are related to the area of artificial intelligence, Internet of things, wireless sensor networks, crowdsourcing, remote sensing, social network analysis, unmanned aerial vehicles (UAV), satellite, and social media.

The keyword co-occurrence analysis depicted the technologies and leading concept in the domain of ICT-assisted smart disaster management: It is identified that ICT-assisted smart disaster management research field is related to the research areas: information management, remote sensing, social networking (online), artificial intelligence, wireless sensor network, Internet of things, big data, data mining, ad hoc network, classification, crowdsourcing, machine learning, deep learning, cloud computing, and sensor network. Furthermore, the co-occurrence analysis depicted the year-wise technological trends and identified cloud computing, the Internet of things, graph theory, data mining, crowdsourcing, learning system, and social media. Furthermore, there has been recent progress in various research areas, including deep neural network, sentimental analysis, cloud computing, IoT, 5G mobile communication, data analytics, and social networking as the current technological trends in the ICT-assisted smart disaster management. Therefore, this scientometric study provides a fundamental structure for researchers to identify the resource and knowledge in the disaster management field. The research areas related to disaster management have increased enormous importance with the period and are shifting in new trends by fusion with the most recent ICT technologies.

The outcomes of this study help for future research and facilitate administrators, the scientific community, industrialists, and policymakers to make well-informed decisions in this domain. From the perspective of future work, this study can explore the various research 
topics and facilitates researchers to design a framework related to disaster management using the latest technologies of ICT, such as IoT, fog computing, and cloud computing.

\section{References}

Abbasi AA, Younis M (2007) A survey on clustering algorithms for wireless sensor networks. Comput Commun 30(14):2826-2841. https://doi.org/10.1016/j.comcom.2007.05.024

Altay N, Green WG (2006) Or/ms research in disaster operations management. Eur J Oper Res 175(1):475493. https://doi.org/10.1016/j.ejor.2005.05.016

Barnes B, Dunn S, Wilkinson S (2019) Natural hazards, disaster management and simulation: a bibliometric analysis of keyword searches. Nat Hazards 97:813-840. https://doi.org/10.1007/s11069-019-03677-2

Bharosa N, Lee J, Janssen M (2010) Challenges and obstacles in sharing and coordinating information during multi-agency disaster response: propositions from field exercises. Inf Syst Front 12:49-65. https:// doi.org/10.1007/s10796-009-9174-Z

Biljecki F (2016) A scientometric analysis of selected giscience journals. Int J Geogr Inf Sci 30(7):13021335. https://doi.org/10.1080/13658816.2015.1130831

Boulos MNK, Resch B, Crowley DN, Breslin JG, Sohn G, Burtner R, Pike WA, Jezierski E, Chuang KYS (2011) Crowdsourcing, citizen sensing and sensor web technologies for public and environmental health surveillance and crisis management: trends, ogc standards and application examples. Int J Health Geogr. https://doi.org/10.1186/1476-072X-10-67

Brewer E, Demmer M, Du B, Ho M, Kam M, Nedevschi S, Pal J, Patra R, Surana S, Fall K (2005) The case for technology in developing regions. Computer 38(6):25-38. https://doi.org/10.1109/MC.2005.204

Chen C (2017) Science mapping: a systematic review of the literature. J Data Inf Sci 2(2):1-40. https://doi. org/10.1515/jdis-2017-0006

Chen C (2019) http://cluster.cis.drexel.edu/ cchen/citespace/. Accessed 14 Oct 2020

Chen Y, Wu C (2017) The hot spot transformation in the research evolution of maker. Scientometrics 113:1307-1324. https://doi.org/10.1007/s11192-017-2542-4

Cobo M, Lopez-Herrera AG, Herrera-Viedma E, Herrera F (2012) Scimat: a new science mapping analysis software tool. J Am Soc Inform Sci Technol 63:1609-1630. https://doi.org/10.1002/asi.22688

de Albuquerque JP, Herfort B, Brenning A, Zipf A (2015) A geographic approach for combining social media and authoritative data towards identifying useful information for disaster management. Int $\mathbf{J}$ Geogr Inf Sci 29(4):667-689. https://doi.org/10.1080/13658816.2014.996567

Debarati GS, Hoyois P, Below R (2016) Annual disaster statistical review 2015 the numbers and trends. Tech. rep., Centre for Research on the Epidemiology of Disasters (CRED). https://www.cred.be/sites/ default/files/ADSR_2015.pdf

Du L, Feng Y, Tang LY, Kang W, Lu W (2020) Networks in disaster emergency management: a systematic review. Nat Hazards 103:1-27. https://doi.org/10.1007/s11069-020-04009-5

Erdelj M, Natalizio E, Chowdhury KR, Akyildiz IF (2017) Help from the sky: leveraging UAVs for disaster management. IEEE Pervasive Comput 16(1):24-32. https://doi.org/10.1109/MPRV.2017.11

Galetsi P, Katsaliaki K (2019) A review of the literature on big data analytics in healthcare. J Oper Res Soc. https://doi.org/10.1080/01605682.2019.1630328

Groger G, Plumer L (2012) Citygml- interoperable semantic 3D city models. ISPRS J Photogramm Remote Sens 71:12-33. https://doi.org/10.1016/j.isprsjprs.2012.04.004

Grothmann T, Reusswig F (2006) People at risk of flooding: Why some residents take precautionary action while others do not. Nat Hazards 38:101-120. https://doi.org/10.1007/s11069-005-8604-6

Guha-Sapir D, Vos F, Below R, Ponserre S (2012) Annual disaster statistical review 2011: the numbers and trends. Tech. rep., The centre for research on the epidemiology of disasters. www.preventionweb.net/ files/27782_adsr2011.pdf

Gupta A, Lamba H, Kumaraguru P, Joshi A (2013) Faking sandy: characterizing and identifying fake images on twitter during hurricane sandy. In: Proceedings of the 22nd international conference on World Wide Web, association for computing machinery, New York, NY, USA, WWW'13 Companion, pp 729-736. https://doi.org/10.1145/2487788.2488033

Han W, Yang Z, Di L, Mueller R (2012) Cropscape: a web service based application for exploring and disseminating us conterminous geospatial cropland data products for decision support. Comput Electron Agric 84:111-123. https://doi.org/10.1016/j.compag.2012.03.005

Heilig L, VoAY S (2014) A scientometric analysis of cloud computing literature. IEEE Trans Cloud Comput 2(3):266-278. https://doi.org/10.1109/TCC.2014.2321168 
Huang L, Chen K, Zhou M (2020) Climate change and carbon sink: a bibliometric analysis. Environ Sci Pollut Res 27:8740-8758. https://doi.org/10.1007/s11356-019-07489-6

Jacomy M, Venturini T, Heymann S, Bastian M (2014) Forceatlas2, a continuous graph layout algorithm for handy network visualization designed for the Gephi software. PLoS ONE 9(6):1-12. https://doi. org/10.1371/journal.pone.0098679

Kamruzzaman M, Sarkar NI, Gutierrez J, Ray SK (2017) A study of iot-based post-disaster management. In: 2017 international conference on information networking (ICOIN), pp 406-410. https:// doi.org/10.1109/ICOIN.2017.7899468

Kaur A, Sood SK (2019) Analytical mapping of research on disaster management, types and role of ICT during 2011-2018. Environ Hazards 18(3):266-285. https://doi.org/10.1080/17477891.2019.15674 57

Kaur A, Sood SK (2020) Ten years of disaster management and use of ICT: a scientometric analysis. Earth Sci Inf 13:1-27. https://doi.org/10.1007/s12145-019-00408-w

Kim J, Hastak M (2018) Social network analysis: characteristics of online social networks after a disaster. Int J Inf Manag 38(1):86-96. https://doi.org/10.1016/j.ijinfomgt.2017.08.003

King D (2007) Organisations in disaster. Nat Hazards 40:657-665. https://doi.org/10.1007/s1106 9-006-9016-y

Manoj B, Baker AH (2007) Communication challenges in emergency response. Commun ACM 50(3):51-53. https://doi.org/10.1145/1226736.1226765

Maza I, Caballero F, Capitan J, de Dios JRM, Ollero A (2011) Experimental results in multi-UAV coordination for disaster management and civil security applications. J Intell Robot Syst 61:563-585. https://doi.org/10.1007/s10846-010-9497-5

Moreira A, Krieger G, Hajnsek I, Papathanassiou K, Younis M, Lopez-Dekker P, Huber S, Villano M, Pardini M, Eineder M, Zan FD, Parizzi A (2015) Tandem-l: a highly innovative bistatic SAR mission for global observation of dynamic processes on the earth's surface. IEEE Geosci Remote Sens Mag 3(2):8-23. https://doi.org/10.1109/MGRS.2015.2437353

Murray-Tuite P, Wolshon B (2013) Evacuation transportation modeling: an overview of research, development, and practice. Transp Res Part C Emerging Technol 27:25-45. https://doi.org/10.1016/j. trc.2012.11.005 ((selected papers from the Seventh Triennial Symposium on Transportation Analysis (TRISTAN VII)))

Noyan N (2012) Risk-averse two-stage stochastic programming with an application to disaster management. Comput Oper Res 39(3):541-559. https://doi.org/10.1016/j.cor.2011.03.017

Saadatseresht M, Mansourian A, Taleai M (2009) Evacuation planning using multiobjective evolutionary optimization approach. Eur J Oper Res 198(1):305-314. https://doi.org/10.1016/j.ejor.2008.07.032

Sahil Sood SK (2020) Bibliometric monitoring of research performance in ICT-based disaster management literature. Qual Quant. https://doi.org/10.1007/s11135-020-00991-X

Senaratne H, Mobasheri A, Ali AL, Capineri C, Haklay MM (2017) A review of volunteered geographic information quality assessment methods. Int J Geogr Inf Sci 31(1):139-167. https://doi. org/10.1080/13658816.2016.1189556

Shan S, Zhao F, Wei Y, Liu M (2019) Disaster management 2.0: a real-time disaster damage assessment model based on mobile social media data-a case study of Weibo (Chinese twitter). Saf Sci 115:393-413. https://doi.org/10.1016/j.ssci.2019.02.029

Sinha A, Kumar P, Rana NP, Islam R, Dwivedi YK (2019) Impact of internet of things (iot) in disaster management: a task-technology fit perspective. Ann Oper Res 283:759-794. https://doi. org/10.1007/s 10479-017-2658-1

Song J, Zhang H, Dong W (2016) A review of emerging trends in global PPP research: analysis and visualization. Scientometrics 107:1111-1147. https://doi.org/10.1007/s11192-016-1918-1

Thayaparan M, Malalgoda C, Keraminiyage K, Amaratunga D (2014) Disaster management education through higher education-industry collaboration in the built environment. Procedia Econ Finance 18:651-658. https://doi.org/10.1016/S2212-5671(14)00987-3 (4th International Conference on Building Resilience, Incorporating the 3rd Annual Conference of the ANDROID Disaster Resilience Network, 8th - 11th September 2014, Salford Quays, United Kingdom)

Tralli DM, Blom RG, Zlotnicki V, Donnellan A, Evans DL (2005) Satellite remote sensing of earthquake, volcano, flood, landslide and coastal inundation hazards. ISPRS J Photogramm Remote Sens 59(4):185-198. https://doi.org/10.1016/j.isprsjprs.2005.02.002 ((remote sensing and geospatial information for natural hazards characterization))

van Eck NJ, Waltman L (2010) Software survey: Vosviewer, a computer program for bibliometric mapping. Scientometrics 84:523-538. https://doi.org/10.1007/s11192-009-0146-3

van Eck NJ, Waltman L (2014) Visualizing bibliometric networks. Springer, Cham, pp 285-320. https:// doi.org/10.1007/978-3-319-10377-8_13 
Verrucci E, Perez-Fuentes G, Rossetto T, Bisby L, Haklay M, Rush D, Rickles P, Fagg G, Joffe H (2016) Digital engagement methods for earthquake and fire preparedness: a review. Nat Hazards 83:15831604. https://doi.org/10.1007/s11069-016-2378-x

Xu Z, Yu D (2019) A bibliometrics analysis on big data research (2009-2018). J Data Inform Manag 1:315. https://doi.org/10.1007/s42488-019-00001-2

Publisher's Note Springer Nature remains neutral with regard to jurisdictional claims in published maps and institutional affiliations. 